\title{
Multispectral Sensing and Data Integration for the Study of Heritage Architecture ${ }^{+}$
}

\author{
Efstathios Adamopoulos 1,*, Fulvio Rinaudo ${ }^{2}$, Monica Volinia ${ }^{2}$ and Mario Girotto ${ }^{2}$ \\ 1 Dipartimento di Informatica, Università degli Studi di Torino, Corso Svizzera 185, 10149 Torino, Italy \\ 2 Dipartimento di Architettura e Design, Politecnico di Torino, Viale P.A. Mattioli 39, 10125 Torino, Italy; \\ fulvio.rinaudo@polito.it (F.R.); monica.volinia@polito.it (M.V.); mario.girotto@polito.it (M.G.) \\ * Correspondence: efstathios.adamopoulos@unito.it \\ + Presented at the 7th International Electronic Conference on Sensors and Applications, 15-30 November \\ 2020; Available online: https://ecsa-7.sciforum.net/.
}

Published: 15 November 2020

\begin{abstract}
Recording and processing of terrestrial multispectral information can have significant value for built heritage studies. The efficient adoption of active and passive sensing techniques operating at multiple wavelengths and the integrated analyses of the produced data is essential for enhanced observation on historical architecture; especially for the implementation of rapid nondestructive surveys, which can provide with an overall assessment for the state-of-preservation of a historical structure to indicate areas of interest for more detailed diagnostics. Based on this rationale, the presented work aims at providing methods for prompt recording, fusion, and integrated visual analysis of two-dimensional multispectral results to study architectural heritage. Spectral images - captured with a modified digital camera-, thermograms, photogrammetrically produced orthophoto-maps, and spatial raster data produced from point clouds, are integrated and analyzed. The results are evaluated from the scope of studying building materials, deterioration patterns, and hidden defects, towards the employment of advanced geomatics approaches to monitor built heritage effectively.
\end{abstract}

Keywords: cultural heritage survey; terrestrial laser scanning; photogrammetry; multispectral imaging; infrared thermography; non-destructive testing

\section{Introduction and Objectives}

Historical buildings are particularly valuable cultural heritage assets. The necessity for monitoring and conservation of built heritage, through holistic recording and integrated data management approaches, is profound, due to its vulnerability to environmental pressures, natural and human-caused disasters, neglect, and inappropriate conservation interventions [1]. The comprehensive understanding of historical monuments or groups of heritage architecture requires detailed documentation [2] which can be achieved with the application of multidisciplinary investigative procedures [3]. These studies should be performed in non-destructive ways [4], to a great extent, to avoid further damaging the historical buildings. Terrestrial-based recording techniques, employing active and passive sensors, are essential for the non-destructive study of heritage architecture's physical characteristics. Capturing information in multiple wavelengths ranging from the ultraviolet to the infrared provides essential input for detecting historical materials [5] and induced damage or weathering [6]. Optical inspection [7], infrared thermography [8], and recently, multiple-view-stereo (MVS)-based digital photogrammetry $[9,10]$, and terrestrial Light Detection and Radar (LiDAR) [11] are being applied - to produce records containing necessary metric spatial and radiometric information or meta-information-to assist non-destructive observation. The 
combination of metric and qualitative data is often highlighted $[12,13]$ as a means to collect products that can serve as the basis for accurate quantitative measurements. The adoption of multispectral methods allows for the efficient recording and integration of multimodal data [14] to enhance observation and facilitate further non-destructive diagnostical investigations by identifying specific areas of interest [15].

The presented work aims to implement efficient terrestrial-based multispectral sensing and data integration methods and repurpose visual analytics procedures commonly applied for remotesensing datasets to evaluate them for architectural heritage investigations. The assessment of the involved methods is performed from the scope of detecting and classifying historical materials, surface alteration, and hidden defects, to provide preliminary diagnostical assumptions for the stateof-preservation of built heritage, simultaneously proving the necessity for the employment of advanced geomatics approaches for structural health monitoring.

\section{Materials and Methods}

\subsection{Methodology}

The proposed workflows include multi-sensor two-dimensional (2D) scenarios to produce localized measurements and metric three-dimensional (3D) procedures to provide larger-scale accurate ortho-derivatives. The investigated approaches were applied to study the façades of Castello del Valentino, one of the historical residences of the Royal House of Savoy in Turin (Italy), and inscribed as UNESCO World Cultural Heritage Site since 1997. The main (west) façade is overall conserved in good condition; however, parts of the river-facing (east) façade are significantly degraded due to the direct and indirect exposition to moisture.

\subsection{Imagery Data}

The first phase for the terrestrial sensing process was the acquisition of reflectance and emissivity data. Visible and near-infrared (NIR; 0.7-1.4 $\mu \mathrm{m}$ ) reflectance images were taken with a Digital Single-Lens Reflex (DSLR) camera, a Canon Rebel-SL1 (CMOS 22.3 × 14.9 sensor, $3456 \times 5184$ pixels spatial resolution, $4.4 \mu \mathrm{m}$ pixel size), using externally mounted filters for the different spectral bands. Passive thermography images were taken with a FLIR T1030sc camera, which employs an uncooled $1024 \times 768$ Long-Wavelength Infrared (LWIR) detector array $(1,024 \times 768$ pixels spatial resolution, $17 \mu \mathrm{m}$ pixel size, measurement accuracy $\pm 1{ }^{\circ} \mathrm{C}$, thermal sensitivity $20 \mathrm{mK}$ at $+30{ }^{\circ} \mathrm{C}$, spectral range $7.5-14 \mu \mathrm{m})$. The images were corrected from lens distortion after performing calibration for the optical and thermal sensors, using custom-made checkerboard-pattern targets.

\subsection{Multispectral Image Composition}

Image composition involved the creation of multispectral cubes from the images collected with different techniques. Undistorted NIR and thermal images were matched manually with the undistorted RGB images, by identifying common features (on the planes of interest). The necessary projective transformation parameters were calculated in the HyperCube hyperspectral research freeware, and affine transform was used to warp the infrared images using as reference the RGB images. Additionally, RGB images were decomposed to the individual bands, thus producing multispectral cubes with a total of 5 spectral channels (blue, green, red, NIR, LWIR).

\subsection{Multispectral Orthophoto-Mosaic Composition}

An image-based approach involving Structure-From-Motion (SFM) and Dense Multi-View 3D Reconstruction (DMVR) algorithms was also considered to produce larger-scale multispectral results. The RGB imagery from the Rebel-SL1, the NIR imagery, and the RGB imagery from the optical sensor of the T1030sc were combined in a single photogrammetric dataset for the accurate estimation of the external orientation parameters of the cameras during acquisition. Then the $3 \mathrm{D}$ geometry for a part of the main façade was densely reconstructed using only the Rebel-SL1 high-resolution RGB imagery. 
The produced point-cloud was meshed into a model using the Delaunay triangulation algorithm. RGB, NIR, and LWIR images were subsequently used to create three orthophoto-mosaics containing spectral information in combination with the resulting geometry. An adaptive ortho-photo texturing approach was followed to avoid inclination and convergence effects concerning the thermal-range imagery. As for the single-image approach, spectral ortho-imagery was loaded in HyperCube (without any need for further geometrical corrections due to the common spatial reference of the orthophoto-mosaics) five-band multispectral cubes were produced after decomposing the RGB images to individual bands.

\subsection{Raster Range Data}

Point-clouds collected with a FARO Focus 3D $\times 330$ laser scanner were used to generate 3D models of the façades. For each surface under investigation, an artificial plane was calculated best fitted to the flatter/less deteriorated areas and used in CloudCompare to calculate distances from the 3D model, thus creating a raster range map, which could be treated as an imagery product.

\section{Results and Discussion}

Multi-spectral and range images regarding twelve areas on the west and easter facades of Castello den Valentino were exploited through:

- Principal Component Analysis (PCA)

- $\quad$ generation of pseudo-colored images using the five spectral bands and the calculated principal components (PCs)

- $\quad$ generation of color quantized images (CQIs)

- unsupervised K-means clustering-based image segmentation

- $\quad$ edge detection filtering.

To facilitate segmentation procedures and interpretation of visual analytics, the results were cropped according to the thermal images' dimensions. In the following section, some of those areas with the most interesting results are presented.

Figures 1-4 show how image analyses facilitate the identification and classification of decay. While on area 2, we could identify only detachments, discolorations, and small cracks, in area 3, we could observe the severe loss of material, biodeterioration, discoloration, erosion, and large cracks.
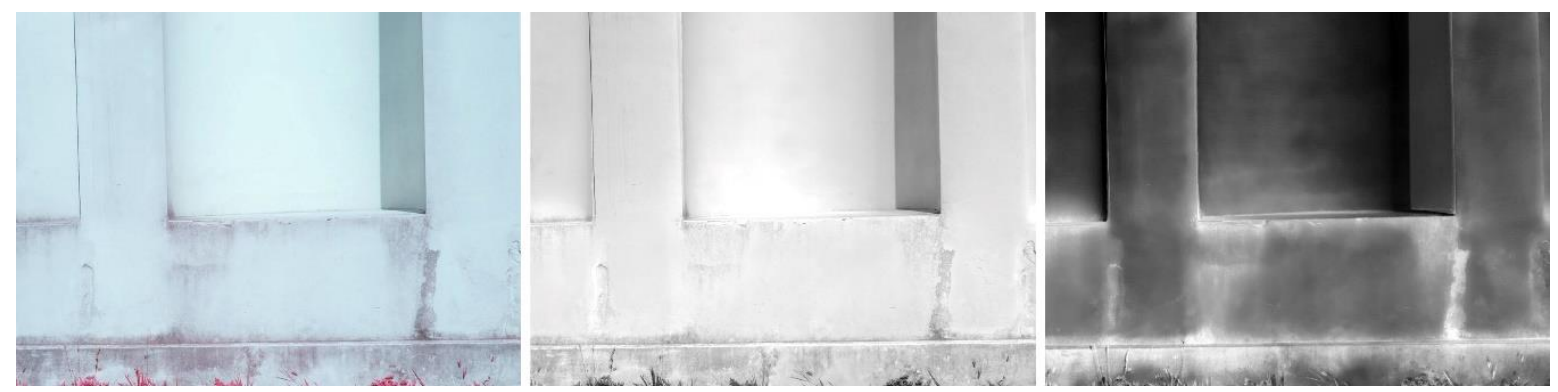

Figure 1. Image analytics, area 2 (from left to right): NIR-R-G composite; PC1; PC2.
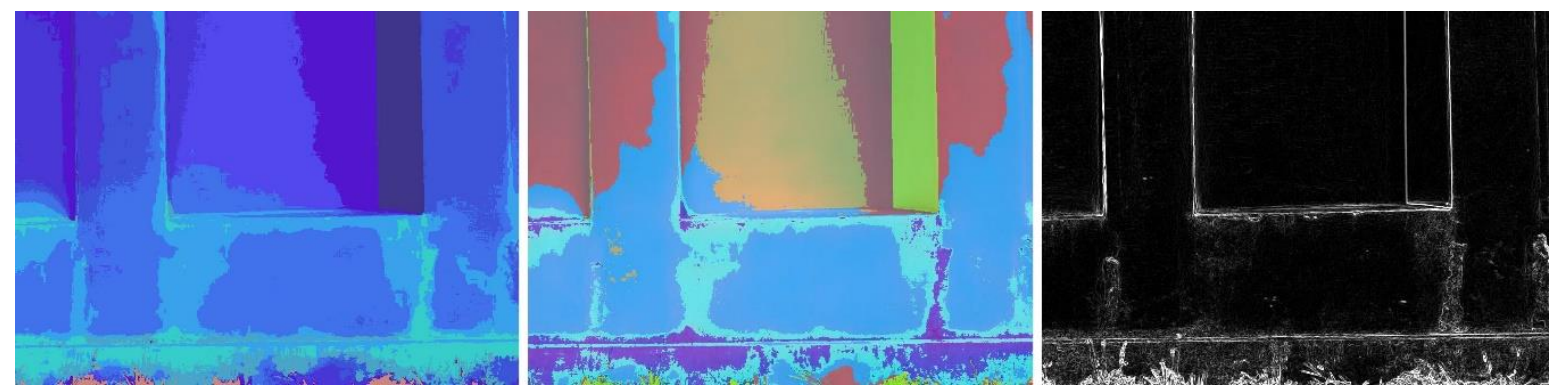
Figure 2. Image analytics, area 2 (from left to right): CQI of composite from first three PCs; 6-class kmeans clustering-based segmentation of TIR-NIR-R composite; 2D-Sobel filtered composite.
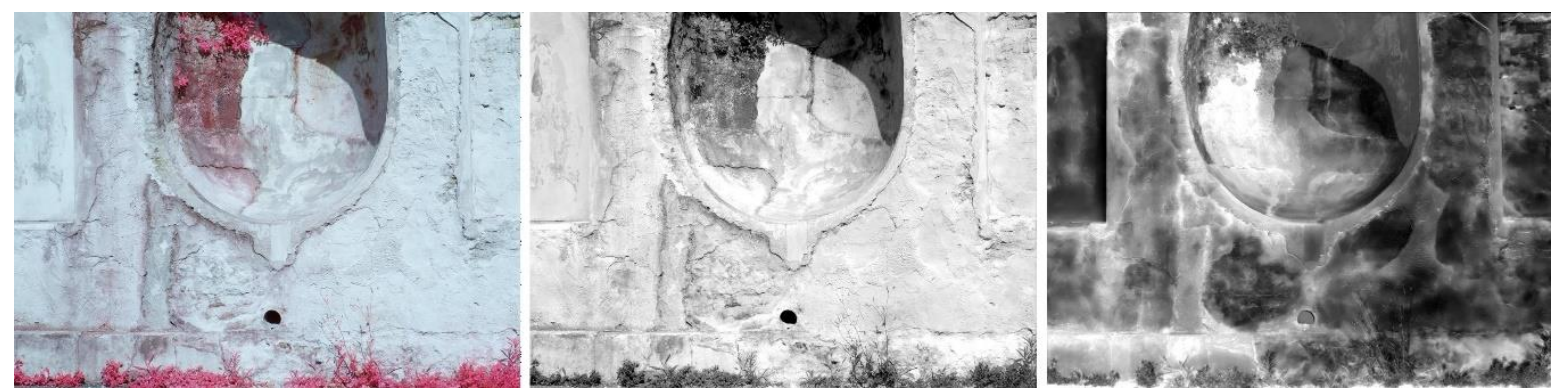

Figure 3. Image analytics, area 3 (from left to right): NIR-R-G composite; PC1; PC2.
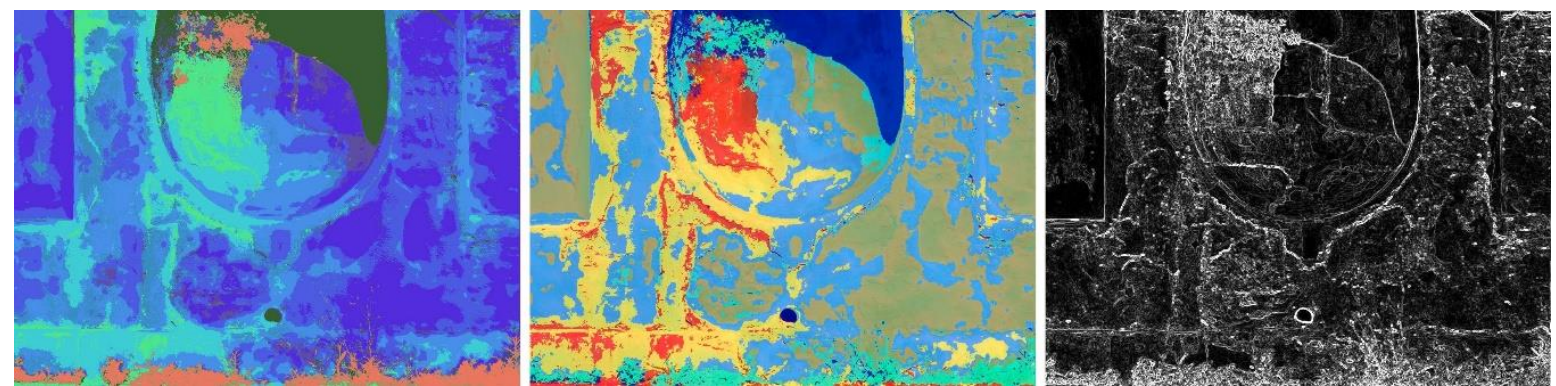

Figure 4. Image analytics, area 3 (from left to right): CQI of composite from first three PCs; 6-class kmeans clustering-based segmentation of TIR-NIR-R composite; 2D-Sobel filtered composite.

The radiometric characteristics identified on the lower part of area 2 (Figure 1 right, and Figure 2 left), combined with the minimal surface degradation observed, led us to identify it as an area of interest for further non-destructive experimentation.

Figures 5 and 6 show how the image analyses assisted the classification of the materials for parts of the main façade, such as the columns. Figure 6 also presents how the existence of anomalies (lower area 7), which leads to anisotropic radiometric characteristics, is resulting in errors regarding the classification of materials. In this case, the visual analytics reveal the position of replacement materials, which will be further studied with additional non-destructive techniques.

Figure 7 presents how pseudo-colored raster images of a shaded visualization and range images can help the interpretation of material loss (area 2).
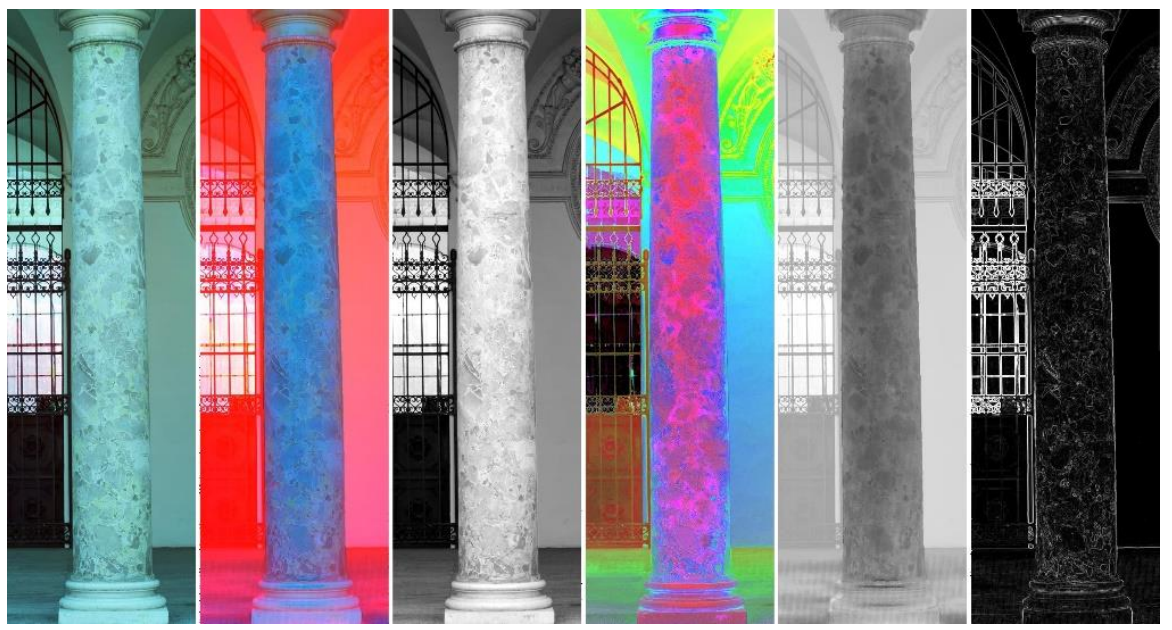

Figure 5. Image analytics, area 6 (from left to right): NIR-R-G composite, TIR-NIR-R composite, PC1, PCs composite, multiband composite, 2D-Sobel filtered multiband composite. 

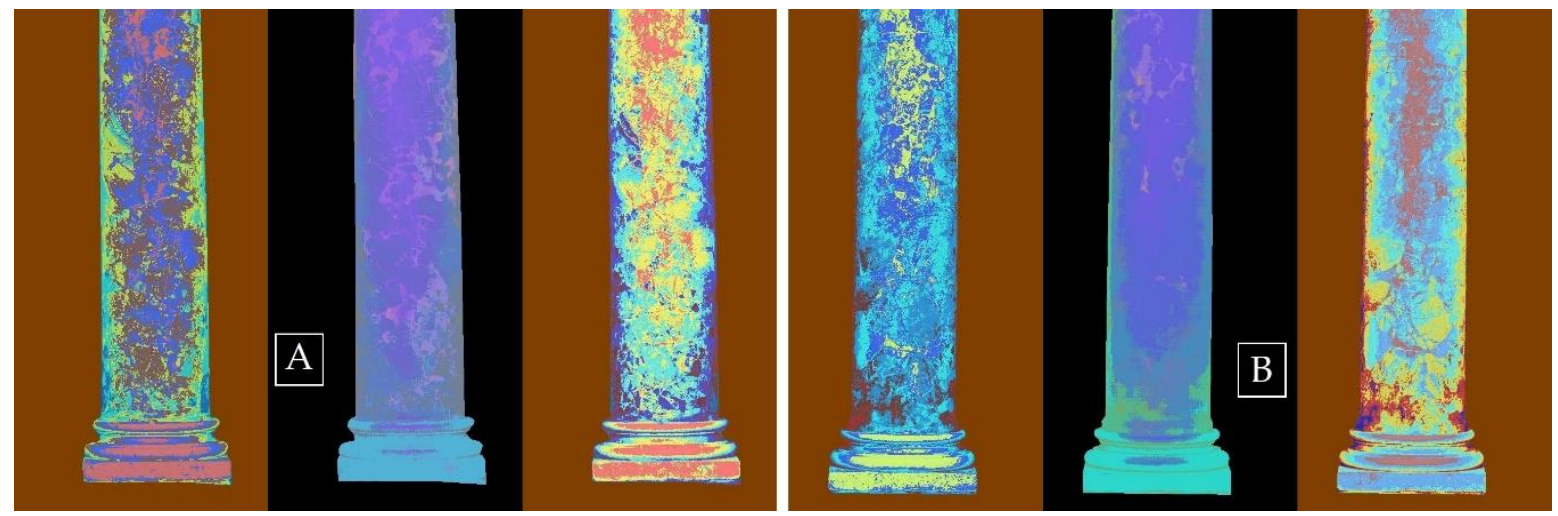

Figure 6. (A): area 6, (from left to right): 7-class k-means clustering-based segmentation of TIR-NIR$\mathrm{R}$ composite, $\mathrm{CQI}$ of composite from first three PCs, 7-class k-means clustering-based segmentation of PC1; (B): area 7, visual analytics as for area 6.
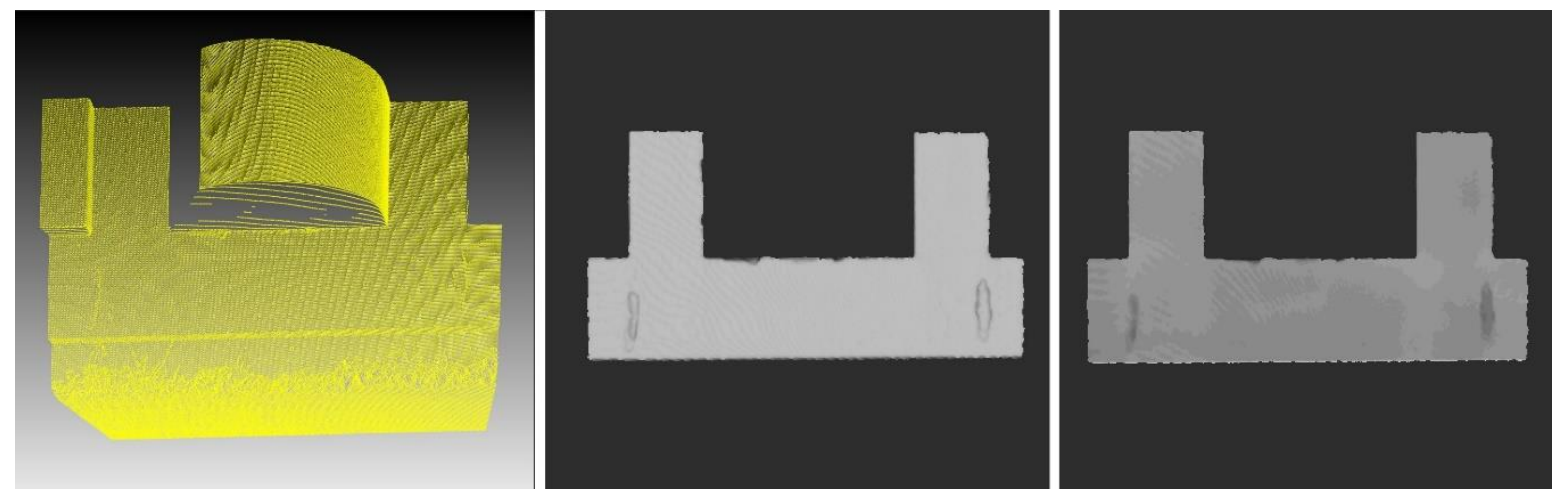

Figure 7. Area 1, (from left to right): 3D point cloud, shaded visualization, grayscale raster range image.

\section{Conclusions}

Image processing techniques applied to integrated multispectral datasets, and visualization techniques applied to laser scanning-derived data, were used to identify and map historical materials and their decay. On occasion, the methods involved proved useful to point out areas where additional non-destructive surveys or minor-destructive tests, involving additional sensors, should be performed. This work shows the potential of terrestrial multispectral sensing for architectural heritage investigations and how techniques otherwise standard for aerial and satellite investigations can be repurposed in this scope. The author's future research will concentrate on calibrating the various sensors to acquire corrected radiometric data in order to perform a more accurate mapping of the materials and decay. The integration in 3D of the data described here, and ground-penetrating radar measurements will also be a focal point for future research.

Author Contributions: Conceptualization, E.A.; Methodology, E.A.; Validation, E.A. and F.R.; Formal analysis, E.A., M.V. and M.G.; Investigation, E.A., F.R., M.V. and M.G.; Resources, E.A., F.R. and M.V.; Data Curation, E.A.; Writing-Original draft, E.A.; Visualization, E.A.; Supervision, F.R. and M.V.; Project administration, M.V. and F.R.; Funding acquisition, F.R.; Writing - review \& editing, F.R., M.V. and M.G. All authors have read and agreed to the published version of this manuscript.

Funding: This project has received funding from the European Union's Framework Program for Research and Innovation Horizon 2020 (2014-2020) under the Marie-Skłodowska Curie Grant Agreement 754511 and the Compagnia di San Paolo Foundation.

Conflicts of Interest: The authors declare no conflict of interest. The funders had no role in the design of the study; in the collection, analyses, or interpretation of data; in the writing of the manuscript, or in the decision to publish the results. 


\section{References}

1. Letellier, R.; Schmid, W.; LeBlanc, F. Recording, Documentation, and Information Management for the Conservation of Heritage Places: Guiding Principles; Getty Conservation Institute: Los Angeles, CA, USA, 2007; ISBN 978-0-89236-925-6.

2. Rinaudo, F. Geomatics tools to record 3D shapes for intervention planning. In World Heritage and Disaster. Knowledge, Culture and Representation, Proceedings of the XVI International Forum 'Le Vie dei Mercanti', Naples, Italy, 15-17 June 2017; La Scuola di Pitagora: Naples, Italy, 2017; pp. 132-139.

3. Kilic, G. Using advanced NDT for historic buildings: Towards an integrated multidisciplinary health assessment strategy. J. Cult. Herit. 2015, 16, 526-535, doi:10.1016/j.culher.2014.09.010.

4. Menéndez, B. Non-Destructive Techniques Applied to Monumental Stone Conservation. In NonDestructive Testing; Garcia Marquez, F.P., Papaelias, M., Zaman, N., Eds.; InTech: Rijeka, Croatia, 2016; ISBN 978-953-51-2501-3.

5. Lerma, J.L. Automatic Plotting of Architectural Facades with Multispectral Images. J. Surv. Eng. 2005, 131, 73-77, doi:10.1061/(ASCE)0733-9453(2005)131:3(73).

6. Pozo, S.D.; Herrero-Pascual, J.; Felipe-García, B.; Hernández-López, D.; Rodríguez-Gonzálvez, P.; González-Aguilera, D. Multi-sensor radiometric study to detect pathologies in historical buildings. Int. Arch. Photogramm. Remote Sens. Spatial Inf. Sci. 2015, XL-5/W4, 193-200, doi:10.5194/isprsarchives-XL-5-W4193-2015.

7. Kapsalas, P.; Maravelaki-Kalaitzaki, P.; Zervakis, M.; Delegou, E.T.; Moropoulou, A. Optical inspection for quantification of decay on stone surfaces. NDT E Int. 2007, 40, 2-11, doi:10.1016/j.ndteint.2006.07.012.

8. Sidiropoulou-Velidou, D.; Georgopoulos, A.; Lerma, J.L. Exploitation of Thermal Imagery for the Detection of Pathologies in Monuments. In Progress in Cultural Heritage Preservation; Ioannides, M., Fritsch, D., Leissner, J., Davies, R., Remondino, F., Caffo, R., Eds.; Lecture Notes in Computer Science; Springer: Berlin/Heidelberg, Germany, 2012; Volume 7616, pp. 97-108; ISBN 978-3-642-34233-2.

9. Peña-Villasenín, S.; Gil-Docampo, M.; Ortiz-Sanz, J. 3-D Modeling of Historic Façades Using SFM Photogrammetry Metric Documentation of Different Building Types of a Historic Center. Int. J. Arch. Herit. 2017, 11, 871-890, doi:10.1080/15583058.2017.1317884.

10. Adamopoulos, E.; Rinaudo, F. Enhancing Image-Based Multiscale Heritage Recording with Near-Infrared Data. IJGI 2020, 9, 269, doi:10.3390/ijgi9040269.

11. Suchocki, C.; Katzer, J.; Serrat, C.; Jagoda, M. Application of TLS Intensity Data for Detection of Brick Walls Defects. IOP Conf. Ser. Mater. Sci. Eng. 2019, 603, 022100, doi:10.1088/1757-899X/603/2/022100.

12. Adamopoulos, E.; Tsilimantou, E.; Keramidas, V.; Apostolopoulou, M.; Karoglou, M.; Tapinaki, S.; Ioannidis, C.; Georgopoulos, A.; Moropoulou, A. Multi-Sensor Documentation of Metric and Qualitative Information of Historic Stone Structures. ISPRS Ann. Photogramm. Remote Sens. Spatial Inf. Sci. 2017, IV2/W2, 1-8, doi:10.5194/isprs-annals-IV-2-W2-1-2017.

13. Adamopoulos, E.; Rinaudo, F. 3D Interpretation and Fusion of Multidisciplinary Data for Heritage Science: A Review. Int. Arch. Photogramm. Remote Sens. Spatial Inf. Sci. 2019, XLII-2/W15, 17-24, doi:10.5194/isprsarchives-XLII-2-W15-17-2019.

14. Hemmleb, M.; Weritz, F.; Schiemenz, A.; Grote, A.; Maierhofer, C. Multi-spectral data acquisition and processing techniques for damage detection on building façades. Int. Arch. Photogramm. Remote Sens. Spatial Inf. Sci. 2006, XXXVI-5.

15. Lerma, J.L.; Cabrelles, M.; Akasheh, T.S.; Haddad, N.A. Documentation of Weathered Architectural Heritage with Visible, near Infrared, Thermal and Laser Scanning Data. Int. J. Herit. Dig. Era 2012, 1, 251275, doi:10.1260/2047-4970.1.2.251.

Publisher's Note: MDPI stays neutral with regard to jurisdictional claims in published maps and institutional affiliations.

(C) 2020 by the authors. Submitted for possible open access publication under the terms and conditions of the Creative Commons Attribution (CC BY) license (http://creativecommons.org/licenses/by/4.0/). 